\title{
A longitudinal Perspective on Efficiency of Airlines in Europe and the U.S
}

\author{
Minh-Anh Thi Nguyen ${ }^{*}$ \\ ${ }^{1}$ Department of Shipping and Transportation Management, National Taiwan Ocean \\ University, Taiwan, ROC; \\ * Corresponding author: minhanh777aof@gmail.com
}

\begin{abstract}
Article History
Received 2021-02-23

Revised 2021-03-03

Accepted 2021-03-04

Published 2021-03-06
\end{abstract}

\section{Keywords}

Airlines in Europe and the US, Efficiency analysis,

Dynamic data envelopment analysis

(Dynamic DEA),

Slack-based measure (SBM).

\section{How to cite?}

Nguyen, M.-A. T. (2021). A

longitudinal Perspective on Efficiency of

Airlines in Europe and the U.S

SEISENSE Journal of Management, 4(2), 11-24. doi:

10.33215 /sjom.v4i2.591
The aviation industries in Europe and the US have been wellestablished since a very early age and have attracted great attention from both industry practitioners and academics. To derive a different perspective on the efficiency levels of airlines operating in the two matured markets, we adopted dynamic data envelopment analysis (DEA). Using the data of the period 2014 - 2016 of 7 European airlines and 9 US airlines that are publicly traded, the study offers an overall picture of airlines' efficiency in the two regions. Notably, the resource flow between the consecutive periods is incorporated into the measure to yield a longitudinal perspective on airlines' efficiency. The study reveals the two major findings. First, most publicly traded airlines in Europe and the US are efficient, except for Hawaiian airline headquartered in the US. Second, Hawaiian airline's inefficiency is majorly contributed by the overuse of the number of employees, consumed fuel, and the deficit of revenue seat-miles in 2014 and 2015. To improve the efficiency level, Hawaiian airlines could consider increasing employee productivity, using more fuel-efficient aircraft, and implementing new marketing strategies to boost sales.

Copyright (C) 2021 The Author(s)

\section{(cc) BY}




\section{Introduction}

In an intensely competitive environment, being efficient has become a major requisition for any business (Liu et al., 2018). Particularly, for the airline industry, which is referred to as a capital-intensive business, efficiency has been of paramount concern to the operators. Understanding the airline's efficiency level benefits airline managers in devising strategies to improve or maintain the company's overall performance, thus strengthening their position on the market.

In response to the need for efficiency measures, there have been several proposed measures. In general, these measures can be majorly categorized into two approaches, namely, non-parametric and parametric. Compared to the parametric approach, the non-parametric approach, which is represented by data envelopment analysis (DEA) has gained greater attention from academics and industry practitioners (Emrouznejad and Yang, 2018). The popularity of DEA as a powerful tool for assessing efficiency can be explained by its ability to handle multiple inputs and outputs and no presumption of production form (Lampe and Hilgers, 2015). Given the superiority of DEA over other methods, it has been widely applied in analyzing the efficiency of the aviation sector (for instance, see comprehensive literature review of Yu et al., 2017; Arjomandi et al., 2018; Cui et al., 2016; Kottasa and Madas, 2018).

The airline industries in Europe and the U.S have been well-established, and underwent different stages of deregulation. The U.S airline industry was first deregulated in 1978. Meanwhile, the European airline industry experienced three phases of slower liberalization initiated in 1987, 1990, and 1993. The differences in the degree of air transport liberalization in these two markets have led to a proliferation of studies comparing the efficiency of airlines in these two regions (Morrell and Taneja, 1979; Good et al., 1993, 1995; Assaf and Josiassen, 2012). Due to the earlier deregulation, the airlines in the U.S seemed to be more efficient than the airlines in Europe (Good et al., 1993, 1995).

In this study, we reinvestigated the efficiency of airlines in Europe and the US. Differing from the prior studies, we adopted DEA measure, a popular tool for efficiency assessment. Furthermore, to provide a longitudinal perspective on airlines' efficiency in the two regions, we employed a dynamic DEA model. The dynamic DEA model could incorporate the resource flow between periods into the efficiency judgment, offering an overview of efficiency levels of decision-making units (DMUs) in the periods (Tone and Tsutsui, 2010). The dynamic DEA model has been successfully applied in evaluating airlines' efficiency in numerous studies (for instance, Omrani and Soltanzadeh, 2016; Yu et al., 2017; Cui et al., 2018). Besides, by using the data of the period 2014 - 2016 of 7 European airlines and 9 US airlines, we updated the overall picture of efficiency levels of the airlines in the two regions.

The paper is structured as follows: Section 2 provides the related literature; Section 3 demonstrates the adopted model for efficiency analysis; Section 4 presents the selection of variables and reports descriptive statistics of selected variables; Section 5 presents and discusses the empirical results; Finally, section 6 summarizes and concludes the major findings.

\section{Literature Review}

Europe and the U.S have presented the most mature markets in the global airline industry. In the past, there have been several studies on the efficiency of airlines of the two regions. For instance, Morrell and Taneja (1979) used ordinary least squares estimation procedure to gauge the efficiency of fourteen U.S and fourteen European airlines in 1975. The study's major findings indicated that the efficiency enhancement could be achieved through more liberty in the air traffic movements, the increase in frequency. The differences in U.S 
and European airlines' efficiency levels could be driven by the differences in service, demand patterns, and route characteristics.

Good et al. (1993) employed Cobb-Douglas single output technology to assess the efficiency of the four largest European air carriers and their eight American counterparts over the period 1976 - 1986. The results of the study suggested that airlines in the US appeared to be more efficient compared to their European counterparts due to the greater liberalization. Also, the potential efficiency enhancement could be obtained by cutting the input resources while the outputs could be fixed at the produced levels.

Good et al. (1995) extended their previous study using both the parametric approach - Cobb-Douglas single output technology and non-parametric approach - data envelopment analysis (DEA) for their efficiency evaluation. The period 1976-1986 for the analysis was the time that the aviation industry in the US was significantly deregulated while the aviation market in Europe remained protected. The study found that the European airlines were less efficient than US airlines 15-20\% on average. Considering resource consumption, airlines in Europe would have saved approximately $\$ 4$ billion per year. Additionally, the authors specified the limitation of a parametric approach in providing upward biases in allocative efficiency estimations.

Assaf and Josiassen (2012) adopted a parametric approach - Bayesian distance frontier model to measure and compare the efficiency and productivity of 17 European and 13 US air carriers during the period $2001-2008$. By imposing regularity conditions on the distance frontier model, the authors found that the European airlines were generally more efficient than the US airlines and displayed better productivity growth over the period. The low-cost carriers in both regions appeared to be more efficient than the full-service carriers.

In general, the existing studies on the efficiency of European and U.S airlines employed parametric approaches. As addressed in previous studies (Lampe and Hilgers, 2015), the major limitation of parametric approach is due to its presumption of relationships between inputs and outputs. Furthermore, it can be seen that most of the previous studies focused on the efficiency change/ productivity change over the periods; however, they ignored the linkage between the periods. The productions between periods are interrelated. According to Tone and Tsutsui (2011, 2014), such relationships can be demonstrated by carry-over activities/ products. Specifically, the products resulted from the production of a period join the production of a subsequent period. Such transitions of resources between periods involve in a dynamic production structure.

Several studies have used the dynamic production structure to investigate airline's efficiency. For instance, Omrani and Soltanzadeh (2016) used dynamic network DEA to consider both carry-over products and the internal structure of the operation of eight Iranian airlines during the period $2010-2012$. In their study, the structure of Iranian airlines was assumed to contain two stages, namely production and consumption, and the number of seats of the fleet was perceived as carry-over products. The study's major findings indicated that the efficiency levels of Iranian airlines tend to be lower in the production stage.

Yu et al. (2017) also used dynamic network DEA to provide another perspective on airline operation's internal structure and the carry-over activities between periods. In specific terms, the dynamic production of 30 global airlines over the period 2009 - 2012 was decomposed into two stages, namely production and service; the number of self-owned aircraft and the number of waypoints were regarded as the carry-over products. The study reported several important findings as follows: (1) the weight/ the importance assigned to each stage significantly impacted the over efficiency estimations; (2) the overall efficiency of the evaluated airline shown a declining trend over the period; (3) the participation in airline alliances, the total assets, and the GDP affected the efficiency of airlines. 
Cui et al. (2018) employed dynamic DEA to exploit the pollution abatement cost of the 18 global airlines during the period 2008 - 2014. The study denoted the capital stock as the carry-over product over the periods. The major findings of the study include (1) Delta airline demonstrated the largest pollution abatement cost; (2) the pollution abatement cost of most airlines declined over time; (3) the financial crisis in 2008 and the deployment of biofuel aircraft impacted on the changes in pollution abatement cost.

Considering the superiority of DEA in incorporating the dynamic effect in assessing efficiency, the current study applies dynamic DEA. Thus, the current study derives a perspective that is different from the existing studies on European and US airlines. The following section explains our applied model.

\section{Methodology}

We evaluate efficiency of $\mathrm{N}$ airlines - DMUs over $\mathrm{T}$ periods. In each period $t(t=1, \ldots, T)$, each DMU $j(j=1, \ldots, N)$ consumes $\mathrm{M}$ common inputs $\boldsymbol{x}^{(t)}=\left(x_{1}^{(t)}, \ldots, x_{m}^{(t)}, \ldots, x_{M}^{(t)}\right) \in \mathfrak{R}_{+}^{M}$ and the $\mathrm{P}$ common carry-over products which are resulted from the previous period's production $\boldsymbol{c}^{(t-1, t)}=\left(c_{1}^{(t-1, t)}, \ldots, c_{p}^{(t-1, t)}, \ldots, c_{P}^{(t-1, t)}\right) \in \mathfrak{R}_{+}^{P}$ to produce common $\mathrm{S}$ outputs $\boldsymbol{y}^{(t)}=\left(y_{1}^{(t)}, \ldots, y_{r}^{(t)}, \ldots, y_{R}^{(t)}\right) \in \mathfrak{R}_{+}^{R}$ and $\mathrm{P}$ common carry-over products $\boldsymbol{c}^{(t, t+1)}=\left(c_{1}^{(t, t+1)}, \ldots, c_{p}^{(t, t+1)}, \ldots, c_{P}^{(t, t+1)}\right) \in \mathfrak{R}_{+}^{P}$ which will join the production of the next period $(t+1)$. The production of a DMU $\left(\boldsymbol{x}_{o}, \boldsymbol{y}_{o}, \boldsymbol{c}_{o}\right)$ is sketched in Figure 1.

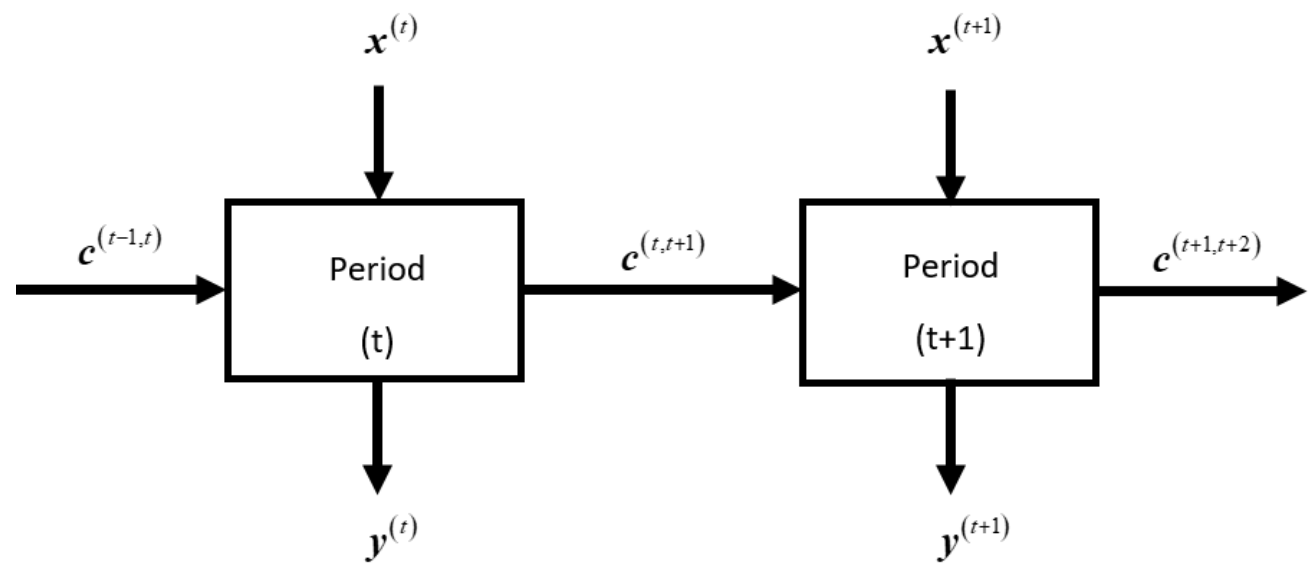

Figure-1. Dynamic structure.

Following Tone and Tsutsui (2010), the carry-over product can be classified into four types, namely good, bad, free, and fixed. The meaning and the constraint for each type are different. Specifically, the good carry-over products are treated as desirable outputs, the bad ones are treated as inputs, the free ones are treated to freely adjusted and supposed to be under the control of DMU, the fixed ones are set fixed at the observed value, and 
supposed to be out of control of DMU. For the details of the constraint representing each type of carry-over product, we refer the readers to Tone and Tsutsui (2010).

In our study, the carry-over products are not controlled by the airlines, and thus, the fixed type is employed.

Accordingly, the production technology under variable returns to scale (VRS) assumption can be expressed as:

$$
\begin{array}{cc}
T=\left\{(\boldsymbol{x}, \boldsymbol{c}, \boldsymbol{y}): \sum_{j=1}^{N} \lambda_{j}^{(t)} x_{m j}^{(t)} \leq x_{m}^{(t)}\right. & m=1, \ldots, M, \quad t=1, \ldots, T \\
\sum_{j=1}^{N} \lambda_{j}^{(t)} c_{p j}^{(t-1, t)}=c_{p}^{(t-1, t)} & p=1, \ldots, P, \quad t=1, \ldots T \\
\sum_{j=1}^{N} \lambda_{j}^{(t)} y_{r j}^{(t)} \geq y_{r}^{(t)} & r=1, \ldots, R, \quad t=1, \ldots T \\
\sum_{j=1}^{N} \lambda_{j}^{(t)} c_{p j}^{(t, t+1)}=c_{p}^{(t, t+1)} & p=1, \ldots, P, \quad t=1, \ldots T \\
\sum_{j=1}^{N} \lambda_{j}^{(t)}=1 & \\
\lambda_{j}^{(t)} \geq 0 & \\
& \\
& \\
&
\end{array}
$$

In which, $\lambda^{(t)}$ is intensity variable which establishes the linear combinations of variables in the production of period $t(t=1, \ldots T)$.

It should be noted that the assumption of fixed carry-over products ensures the continuity of resource flow between periods ( $t-1)$ and $t$, and between periods $t$ and $(t+1)$, thus, there is no necessity to include the constraints $\sum_{j=1}^{N} \lambda_{j}^{(t-1)} c_{p j}^{(t-1, t)}=\sum_{j=1}^{N} \lambda_{j}^{(t)} c_{p j}^{(t-1, t)}(t=2, \ldots, T)$

To seek the simultaneous maximum potential input excesses and output shortfalls, the non-oriented dynamic slack-based measure (DSBM) model is adopted for assessing efficiency of US airlines. The dynamic efficiency of the evaluated DMU $\left(\boldsymbol{x}_{o}, \boldsymbol{y}_{o}, \boldsymbol{c}_{o}\right)$ can be estimated by solving the following mathematical problem:

$$
\operatorname{Min} \frac{\sum_{t=1}^{T} w^{t} \cdot\left(1-\frac{1}{M} \sum_{m=1}^{M} \frac{s_{m o}^{(t)(-)}}{x_{m o}^{(t)}}\right)}{\sum_{t=1}^{T} w^{t} \cdot\left(1+\frac{1}{R} \sum_{r=1}^{R} \frac{s_{r o}^{(t)(+)}}{y_{r o}^{(t)}}\right)}
$$


Subject to: $\quad \sum_{j=1}^{N} \lambda_{j}^{(t)} x_{m j}^{(t)}=x_{m o}^{(t)}-S_{m o}^{(t)(-)}$

$$
\begin{array}{ll}
\sum_{j=1}^{N} \lambda_{j}^{(t)} c_{p j}^{(t-1, t)}=c_{p o}^{(t-1, t)} & p=1, \ldots, P, \quad t=1, \ldots T \\
\sum_{j=1}^{N} \lambda_{j}^{(t)} y_{r j}^{(t)}=y_{r o}^{(t)}+s_{r o}^{(t)(+)} & r=1, \ldots, R, \quad t=1, \ldots T \\
\sum_{j=1}^{N} \lambda_{j}^{(t)} c_{p j}^{(t, t+1)}=c_{p}^{(t, t+1)} & p=1, \ldots, P, \quad t=1, \ldots T \\
\sum_{j=1}^{N} \lambda_{j}^{(t)}=1 & t=1, \ldots T \\
\lambda_{j}^{(t)} \geq 0 & j=1, \ldots, N, \quad t=1, \ldots T \\
S_{m o}^{(t)(-)}, S_{r o}^{(t)(+)} \geq 0, & m=1, \ldots, M, \quad r=1, \ldots, R, \quad t=1, \ldots, T
\end{array}
$$

In which, $s_{m o}^{(t)(-)}, s_{r o}^{(t)(+)}$ are slacks of input and output in period $t$ respectively, $w_{t}$ is the weight/ importance of each period in the whole evaluated period, $\sum_{t=1}^{T} w_{t}=1$. The objective of the model (2) is to seek the maximum slacks of inputs and outputs in each period.

As model (2) is in nonlinear form, to transform it into linear form, the Charnes-Cooper transformation is adapted (Tone, 2001). Multiplying both the denominator and numerator with $k(k>0)$, the denominator is then set to be equal to 1 . The model (2) then takes the following form:

$\operatorname{Min} \sum_{t=1}^{T} w^{t} \cdot\left(k-\frac{1}{M} \sum_{m=1}^{M} \frac{k \cdot s_{m o}^{(t)(-)}}{x_{m o}^{(t)}}\right)$

Subject to $\quad \sum_{t=1}^{T} w^{t} \cdot\left(k+\frac{1}{R} \sum_{r=1}^{R} \frac{k \cdot s_{r o}^{(t)(+)}}{y_{r o}^{(t)}}\right)=1$

$$
\begin{array}{ll}
\sum_{j=1}^{N} k \cdot \lambda_{j}^{(t)} x_{m j}^{(t)}=k \cdot x_{m o}^{(t)}-k \cdot s_{m o}^{(t)(-)} & m=1, \ldots, M, t=1, \ldots, T \\
\sum_{j=1}^{N} k \cdot \lambda_{j}^{(t)} c_{p j}^{(t-1, t)}=k \cdot c_{p o}^{(t-1, t)} & p=1, \ldots, P, \quad t=1, \ldots T \\
\sum_{j=1}^{N} k \cdot \lambda_{j}^{(t)} y_{r j}^{(t)}=k \cdot y_{r o}^{(t)}+k \cdot s_{r o}^{(t)(+)} & r=1, \ldots, R, \quad t=1, \ldots T
\end{array}
$$




$$
\begin{array}{ll}
\sum_{j=1}^{N} k \cdot \lambda_{j}^{(t)} c_{p j}^{(t, t+1)}=k \cdot c_{p}^{(t, t+1)} & p=1, \ldots, P, \quad t=1, \ldots T \\
\sum_{j=1}^{N} k \cdot \lambda_{j}^{(t)}=k & t=1, \ldots T \\
\lambda_{j}^{(t)} \geq 0 & j=1, \ldots, N, \quad t=1, \ldots T \\
S_{m o}^{(t)(-)}, s_{r o}^{(t)(+)} \geq 0, & m=1, \ldots, M, \quad r=1, \ldots, R, \quad t=1, \ldots, T \\
k>0 &
\end{array}
$$

Let us define $\quad k \cdot s_{m o}^{(t)(-)}=S_{m o}^{(t)(-)}(m=1, \ldots, M ; t=1, \ldots, T) ; k \cdot S_{r o}^{(t)(+)}=S_{r o}^{(t)(+)}(r=1, \ldots, R ; t=1, \ldots, T)$; $k \cdot \lambda_{j}^{(t)}=\Lambda_{j}^{(t)}(j=1, \ldots, N ; t=1, \ldots, T)$. The model (3) then takes the following form:

Min

$$
\sum_{t=1}^{T} w^{t} \cdot\left(k-\frac{1}{M} \sum_{m=1}^{M} \frac{S_{m o}^{(t)(-)}}{x_{m o}^{(t)}}\right)
$$

Subject to

$$
\begin{array}{ll}
\sum_{t=1}^{T} w^{t} \cdot\left(k+\frac{1}{R} \sum_{r=1}^{R} \frac{S_{r o}^{(t)(+)}}{y_{r o}^{(t)}}\right)=1 & \\
\sum_{j=1}^{N} \Lambda_{j}^{(t)} x_{m j}^{(t)}=k \cdot x_{m o}^{(t)}-S_{m o}^{(t)(-)} & m=1, \ldots, M, t=1, \ldots, T \\
\sum_{j=1}^{N} \Lambda_{j}^{(t)} c_{p j}^{(t-1, t)}=k \cdot c_{p o}^{(t-1, t)} & p=1, \ldots, P, \quad t=1, \ldots T \\
\sum_{j=1}^{N} \Lambda_{j}^{(t)} y_{r j}^{(t)}=k \cdot y_{r o}^{(t)}+S_{r o}^{(t)(+)} & r=1, \ldots, R, \quad t=1, \ldots T \\
\sum_{j=1}^{N} \Lambda_{j}^{(t)} c_{p j}^{(t, t+1)}=k \cdot c_{p}^{(t, t+1)} & p=1, \ldots, P, \quad t=1, \ldots T \\
\sum_{j=1}^{N} \Lambda_{j}^{(t)}=k & t=1, \ldots T \\
\Lambda_{j}^{(t)} \geq 0 & j=1, \ldots, N, \quad t=1, \ldots T \\
S_{m o}^{(t)(-)}, S_{r o}^{(t)(+)} \geq 0, & m=1, \ldots, M, \quad r=1, \ldots, R, \quad t=1, \ldots, T \\
k>0 &
\end{array}
$$

Let us denote the optimal solution of the model (4) with asterisk, the optimal solution to (3) can be defined as: 


$$
\begin{aligned}
& S_{m o}^{(t)(-)^{*}}=\frac{S_{m o}^{(t)(-)^{*}}}{k^{*}},(m=1, \ldots, M ; t=1, \ldots, T), \\
& s_{r o}^{(t)(+)^{*}}=\frac{S_{r o}^{(t)(+)^{*}}}{k^{*}},(r=1, \ldots, R ; t=1, \ldots, T), \\
& \lambda_{j}^{(t)}=\frac{\Lambda_{j}^{(t) *}}{k^{*}},(j=1, \ldots, N ; t=1, \ldots, T) .
\end{aligned}
$$

The efficiency of DMU $\left(\boldsymbol{x}_{o}, \boldsymbol{y}_{o}, \boldsymbol{c}_{o}\right)$ in period $t(t=1, \ldots, T)$ can be estimated as follows:

$$
E_{o}^{(t)}=\frac{1-\frac{1}{M} \sum_{m=1}^{M} \frac{s_{m o}^{(t)(-) *}}{x_{m o}^{(t)}}}{1+\frac{1}{R} \sum_{r=1}^{R} \frac{s_{r o}^{(t)(+)^{*}}}{y_{r o}^{(t)}}}
$$

The dynamic efficiency of DMU $\left(\boldsymbol{x}_{o}, \boldsymbol{y}_{o}, \boldsymbol{c}_{o}\right)$ over the T period can be determined as:

$$
E_{o}=\frac{\sum_{t=1}^{T} w^{t} \cdot\left(1-\frac{1}{M} \sum_{m=1}^{M} \frac{s_{m o}^{(t)(-)^{*}}}{x_{m o}^{(t)}}\right)}{\sum_{t=1}^{T} w^{t} \cdot\left(1+\frac{1}{R} \sum_{r=1}^{R} \frac{s_{r o}^{(t)(+)^{*}}}{y_{r o}^{(t)}}\right)}
$$

\section{Data and variables selection}

In this study, we considered 9 US airlines (Alaska, Allegiant, Delta, Hawaiian, JetBlue, Skywest, Southwest, Spirit, and United Airlines) and 7 European airlines (Aegean, British Airways, easyJet, Lufthansa, Norwegian, Ryanair, and Wizz Air) over the period 2014-2016. The selected airlines are among the largest airlines operating in Europe and the US, thus representing the two regions' aviation industry. Besides, their parent companies are publicly-traded, which makes their data more transparent.

The selection of inputs, outputs, and carry-over products was made based on the availability of data and the existing literature. Regarding input variables, three inputs were chosen, namely full-time equivalent employees, fuel consumption, and available seat miles (ASMs). The variable of labor has been commonly used as input in efficiency evaluation in the airline industry (Assaf and Josiassen, 2012; Merkert and Williams, 2013; Yu et al., 2016; Chang and Yu, 2014; Merkert and Pearson, 2015; Saranga and Nagpal, 2016; Cao et al., 2015; Arjomandi et al., 2018; Barros and Wanke, 2015; Kottas and Madas, 2018). Fuel presents one of the most critical materials for an airline operation. The selection of this variable is consistent with prior studies (Tsionas et al., 2017; Cao et al., 2015; Gramani, 2012; Chow, 2010; Yu et al., 2016; Cui and Li, 2017). Besides labor and material inputs, capital input is another critical component for airline operations. Following Merkert and Pearson (2015), Yu et al. (2016), Saranga and Nagpal (2016), Barros and Couto (2013), ASM was treated as capital input. Regarding the output variable, revenue-passenger miles (RPMs) were chosen, representing the passenger traffic volume 
handled by an airline. RPM has been widely accepted as a major output in efficiency evaluation of airlines in prior studies (Merkert and Pearson, 2015; Cui and Li, 2017; Kottas and Madas, 2018, Chang and Yu, 2014; Yu et al., 2017).

Table 1: Descriptive statistics of the selected variables. ${ }^{1}$

\begin{tabular}{|c|c|c|c|c|}
\hline Variables & Minimum & Maximum & Mean & Std. dev. \\
\hline \multicolumn{5}{|l|}{2013} \\
\hline \multicolumn{5}{|l|}{ Carry-over product } \\
\hline Shareholder's equity (million dollars) & 99.4 & $12,772.0$ & $3,047.3$ & $3,359.8$ \\
\hline \multicolumn{5}{|l|}{2014} \\
\hline \multicolumn{5}{|l|}{ Inputs } \\
\hline Number of employees & 1,650 & 79,829 & 21,920 & 26,154 \\
\hline Consumed fuel (million gallons) & 52.7 & $3,265.6$ & $1,051.3$ & $1,110.5$ \\
\hline ASM (million seat-miles) & $8,682.0$ & $211,954.2$ & $83,516.0$ & $76,817.8$ \\
\hline \multicolumn{5}{|l|}{ Output } \\
\hline RPM (million passenger-miles) & $1,632.5$ & $177,553.1$ & $68,692.6$ & $64,391.2$ \\
\hline \multicolumn{5}{|l|}{ Carry-over product } \\
\hline Shareholder's equity (million dollars) & 221.2 & $9,518.0$ & $2,626.8$ & 2626.0 \\
\hline \multicolumn{5}{|l|}{2015} \\
\hline \multicolumn{5}{|l|}{ Inputs } \\
\hline Number of employees & $2,040.0$ & $78,649.0$ & $22,141.3$ & $26,304.7$ \\
\hline Consumed fuel (million gallons) & 55.3 & 3,388.9 & $1,004.9$ & $1,100.6$ \\
\hline ASM (million seat-miles) & $10,223.7$ & $218,138.2$ & $87,013.9$ & $76,978.4$ \\
\hline \multicolumn{5}{|l|}{ Output } \\
\hline RPM (million passenger-miles) & $1,897.1$ & $185,840.9$ & 72429.6 & $65,258.3$ \\
\hline \multicolumn{5}{|l|}{ Carry-over product } \\
\hline Shareholder's equity (million dollars) & 256.2 & 11707.2 & $3,528.7$ & $3,517.9$ \\
\hline \multicolumn{5}{|l|}{2016} \\
\hline \multicolumn{5}{|l|}{ Inputs } \\
\hline Number of employees & 2,093 & 81,002 & 22,940 & 26,793 \\
\hline Consumed fuel (million gallons) & 71.0 & $3,412.6$ & $1,004.4$ & 1,088.9 \\
\hline ASM (million seat-miles) & $11,925.2$ & $223,281.4$ & $91,480.2$ & $78,090.6$ \\
\hline \multicolumn{5}{|l|}{ Output } \\
\hline RPM (million passenger-miles) & $1,713.8$ & $189,706.8$ & $76,477.6$ & $66,212.4$ \\
\hline \multicolumn{5}{|l|}{ Carry-over product } \\
\hline Shareholder's equity (million dollars) & 281.9 & $13,085.7$ & $3,877.4$ & $3,738.9$ \\
\hline
\end{tabular}

Note: The value of shareholder's equity is adjusted for inflation.

Considering the carry-product which connects the two consecutive periods, we used the shareholder's equity. The shareholder's equity of the previous period is treated as an input for the subsequent period. After joining

\footnotetext{
${ }^{1}$ Since the study focuses on the passenger operations, the inputs in our study such as the number of employees and the fuel consumption of combination carriers are supposed to be reported for the passenger operation only. For the reason that there is no such information presented in the reports, like the previous studies on efficiency analysis of airlines, the current study uses the total number of employees and the fuel consumption which might cover the cargo operation.
} 
the production of a period, the amount of shareholder's equity is changed as a business outcome, thus, it can be treated as output. Our selection is in line with prior studies (Alperovych et al., 2013; Lu et al., 2014; Hung et al., 2014).

The data was collected from the annual reports of airline companies. Table 1 reports the descriptive statistics of the data.

\section{Empirical results and discussion}

The dynamic efficiency of Europe and the US was estimated using the model (4) with an assumption of equal weight assigned to each period. The dynamic efficiency estimations are reported in Table 2.

Table 2: Dynamic efficiency of European and US airlines over the period (2014 - 2016).

\begin{tabular}{|c|c|c|c|c|}
\hline Airline & 2014 & 2015 & 2016 & $\begin{array}{l}\text { Overall } \\
2014-2016\end{array}$ \\
\hline \multicolumn{5}{|l|}{ US } \\
\hline Alaska & 1.000 & 1.000 & 1.000 & 1.000 \\
\hline Allegiant & 1.000 & 1.000 & 1.000 & 1.000 \\
\hline Delta & 1.000 & 1.000 & 1.000 & 1.000 \\
\hline Hawaiian & 0.611 & 0.612 & 1.000 & 0.741 \\
\hline JetBlue & 1.000 & 1.000 & 1.000 & 1.000 \\
\hline SkyWest & 1.000 & 1.000 & 1.000 & 1.000 \\
\hline Southwest & 1.000 & 1.000 & 1.000 & 1.000 \\
\hline Spirit & 1.000 & 1.000 & 1.000 & 1.000 \\
\hline United Airlines & 1.000 & 1.000 & 1.000 & 1.000 \\
\hline \multicolumn{5}{|l|}{ European } \\
\hline Aegean & 1.000 & 1.000 & 1.000 & 1.000 \\
\hline British Airways & 1.000 & 1.000 & 1.000 & 1.000 \\
\hline EasyJet & 1.000 & 1.000 & 1.000 & 1.000 \\
\hline Lufthansa & 1.000 & 1.000 & 1.000 & 1.000 \\
\hline Norwegian & 1.000 & 1.000 & 1.000 & 1.000 \\
\hline Ryanair & 1.000 & 1.000 & 1.000 & 1.000 \\
\hline Wizz Air & 1.000 & 1.000 & 1.000 & 1.000 \\
\hline Mean & 0.976 & 0.976 & 1.000 & 0.984 \\
\hline Min & 0.611 & 0.612 & 1.000 & 0.741 \\
\hline Max & 1.000 & 1.000 & 1.000 & 1.000 \\
\hline Std.dv & 0.097 & 0.097 & 0.000 & 0.037 \\
\hline
\end{tabular}

As shown in the overall efficiency of airlines (column 5) in Table 2, all evaluated airlines in Europe and the US were efficient during the period $(2014$ - 2016), except for Hawaiian airline. The airlines which are publicly traded tend to be efficient. With the updated data, we found that the airlines in the US and Europe have now been more comparable in terms of efficiency level. It seems that the significant liberalization of the aviation market in Europe has helped the airlines in this region to catch up with the airlines in the US. 
Furthermore, the adoption of dynamic DEA provides us a longitudinal perspective on airlines' efficiency throughout the analyzed period. Specifically, except for Hawaiian airline, all the evaluated airlines are deemed efficient during $(2014-2016)$. This suggests that the stable and efficient operation of airlines over the period.

In contrast to other airlines, Hawaiian airline seems to be the least efficient one. Specifically, in 2014, and 2015 the airline attains efficiency levels of $61.1 \%$ and $61.2 \%$, respectively. The year 2016 displays a remarkable improvement in Hawaiian airline efficiency with an efficiency score of unity. Thanks to the substantial progress made in 2016, the airline's overall efficiency level during 2014 - 2016 reaches $74.1 \%$. To specify the wastes in input consumption and deficits in the Hawaiian airline's output production, we investigated the input and output slacks of the airlines. The information is recorded in Table 3.

As shown in Table 3, Hawaiian's inefficiency in 2014 is caused by the overuse of 2,373 employees, 45.47 million gallons of fuel, and the shortfall of 989 million revenue passenger miles. Meanwhile, in 2015, the airline has shown the overuse of 2,213 employees, 54.88, and the deficit of 1,080 million revenue passenger miles. In 2016, Hawaiian airline displayed an excellent deployment of resources and a reasonable traffic volume; thus, no slacks are indicated for this year.

Table 3: Input excesses and output shorffalls of European and US airlines over the period (2014 - 2016).

\begin{tabular}{llll}
\hline Airline & 2014 & 2015 & 2016
\end{tabular}

$\begin{array}{lllllllllll}(1) & (2) & (3) & (4) & (1) & (2) & \text { (3) } & \text { (4) } & \text { (1) } & \text { (2) } & \text { (3) }\end{array}$

US

\begin{tabular}{lllllllllllll} 
Alaska & 0 & 0 & 0 & 0 & 0 & 0 & 0 & 0 & 0 & 0 & 0 & 0 \\
Allegiant & 0 & 0 & 0 & 0 & 0 & 0 & 0 & 0 & 0 & 0 & 0 & 0 \\
Delta & 0 & 0 & 0 & 0 & 0 & 0 & 0 & 0 & 0 & 0 & 0 & 0 \\
Hawaiian & $-2,373$ & -45.47 & 0 & +989 & $-2,213$ & -54.88 & 0 & $+1,080$ & 0 & 0 & 0 & 0 \\
JetBlue & 0 & 0 & 0 & 0 & 0 & 0 & 0 & 0 & 0 & 0 & 0 & 0 \\
SkyWest & 0 & 0 & 0 & 0 & 0 & 0 & 0 & 0 & 0 & 0 & 0 & 0 \\
Southwest & 0 & 0 & 0 & 0 & 0 & 0 & 0 & 0 & 0 & 0 & 0 & 0 \\
Spirit & 0 & 0 & 0 & 0 & 0 & 0 & 0 & 0 & 0 & 0 & 0 & 0 \\
United Airlines & 0 & 0 & 0 & 0 & 0 & 0 & 0 & 0 & 0 & 0 & 0 & 0 \\
& & & & & & & & & & & & \\
European & & & & & & & & & & & & \\
Aegean & 0 & 0 & 0 & 0 & 0 & 0 & 0 & 0 & 0 & 0 & 0 & 0 \\
British Airways & 0 & 0 & 0 & 0 & 0 & 0 & 0 & 0 & 0 & 0 & 0 & 0 \\
easyJet & 0 & 0 & 0 & 0 & 0 & 0 & 0 & 0 & 0 & 0 & 0 & 0 \\
Lufthansa & 0 & 0 & 0 & 0 & 0 & 0 & 0 & 0 & 0 & 0 & 0 & 0 \\
Norwegian & 0 & 0 & 0 & 0 & 0 & 0 & 0 & 0 & 0 & 0 & 0 & 0 \\
Ryanair & 0 & 0 & 0 & 0 & 0 & 0 & 0 & 0 & 0 & 0 & 0 & 0 \\
Wizz Air & 0 & 0 & 0 & 0 & 0 & 0 & 0 & 0 & 0 & 0 & 0 & 0 \\
\hline Note: (1): Nimber.
\end{tabular}

Note: (1): Number of employees

(2): Consumed fuel

(3): Available seat-mile

(4): Revenue passenger-mile 


\section{Conclusion}

The study reinvestigates the efficiency of airlines in Europe and the US over the period 2014 - 2016. Notably, this is the first time the transitions of resources between periods have been taken into account. Using the dynamic DEA models, the study offers a longitudinal perspective on the efficiency of publicly traded airlines in Europe and the US. Furthermore, the employment of the airlines' updated data has refreshed the overall picture of airline performance in the two regions.

The study's empirical results suggest that most publicly traded airlines in Europe and the US are efficient. Among 7 European airlines and 9 US airlines, only Hawaiian airline is inefficient with an overall efficiency level of $74.1 \%$ over the period $(2014$ - 2016). Other airlines demonstrate extraordinary performance and maintain it over the period. The inefficiency of Hawaiian airline is majorly contributed by the overuse of the number of employees and consumed fuel and the traffic volume deficit in 2014 and 2015.

Regarding the study's limitation, it can be argued that our study has not dealt with the internal structure of the airline operation. The lack of data drives this limitation as the internal structure typically requires a greater number of input, output, and intermediate product variables. Thus, in the near future, we intend to extend our current study considering the internal structure of airline operation. Such an approach would provide more information on the underlying sources of inefficiency which exist in airline operation.

Additionally, the airlines included in our study adopted different business models such as full-service, low-cost, ultra-low-cost models. Due to the limited number of DMUs in the study, we could not test how the different business models affect the efficiency levels of airlines. Besides, some other concerns about the impacts of aircraft acquisition, network expansion, the economic environment should be addressed in future studies on the condition that the data are available.

Funding: This research received no external funding

Conflicts of Interest: The author declares no conflict of interest.

\section{References}

Alperovych, Y., Amess, K., \& Wright, M. (2013). Private equity firm experience and buyout vendor source: What is their impact on efficiency?. European Journal of Operational Research, 228(3), 601-611. https://doi.org/10.1016/j.ejor.2013.01.019

Arjomandi, A., Dakpo, K. H., \& Seufert, J. H. (2018). Have Asian airlines caught up with European Airlines? A by-production efficiency analysis. Transportation Research Part A: Policy and Practice, 116, 389-403. https://doi.org/10.1016/j.tra.2018.06.031

Assaf, A. G., \& Josiassen, A. (2012). European vs. US airlines: Performance comparison in a dynamic market. Tourism Management, 33(2), 317-326. https://doi.org/10.1016/j.tourman.2011.03.012

Barros, C. P., \& Couto, E. (2013). Productivity analysis of European airlines, 2000-2011. Journal of Air Transport Management, 31, 11-13. https://doi.org/10.1016/j.jairtraman.2012.10.006

Barros, C. P., \& Wanke, P. (2015). An analysis of African airlines efficiency with two-stage TOPSIS and neural networks. Journal of Air Transport Management, 44, 90-102. https://doi.org/10.1016/j.jairtraman.2015.03.002

Cao, Q., Lv, J., \& Zhang, J. (2015). Productivity efficiency analysis of the airlines in China after deregulation. Journal of Air Transport Management, 42, 135-140. https://doi.org/10.1016/j.jairtraman.2014.09.009 
Chang, Y. C., \& Yu, M. M. (2014). Measuring production and consumption efficiencies using the slack-based measure network data envelopment analysis approach: the case of low-cost carriers. Journal of advanced transportation, 48(1), 15-31. https://doi.org/10.1002/atr.198

Chow, C. K. W. (2010). Measuring the productivity changes of Chinese airlines: the impact of the entries of non-state-owned carriers. Journal of Air Transport Management, 16(6), 320-324. https://doi.org/10.1016/j.jairtraman.2010.04.001

Cui, Q., \& Li, Y. (2017). Airline efficiency measures using a Dynamic Epsilon-Based Measure model. Transportation Research Part A: Policy and Practice, 100, 121-134. https://doi.org/10.1016/j.tra.2017.04.013

Cui, Q., Li, Y., \& Lin, J. L. (2018). Pollution abatement costs change decomposition for airlines: An analysis from a dynamic perspective. Transportation Research Part A: Policy and Practice, 111, 96-107. https://doi.org/10.1016/j.tra.2018.03.014

Emrouznejad, A., \& Yang, G. L. (2018). A survey and analysis of the first 40 years of scholarly literature in DEA: 1978-2016. Socio-Economic Planning Sciences, 61, 4-8. https://doi.org/10.1016/j.seps.2017.01.008

Good, D. H., Nadiri, M. I., Röller, L. H., \& Sickles, R. C. (1993). Efficiency and productivity growth comparisons of European and US air carriers: a first look at the data. Journal of Productivity analysis, 4(1-2), 115-125. https://doi.org/10.1007/978-94-011-2200-9_8

Good, D. H., Röller, L. H., \& Sickles, R. C. (1995). Airline efficiency differences between Europe and the US: implications for the pace of EC integration and domestic regulation. European Journal of Operational Research, 80(3), 508-518. https://doi.org/10.1016/0377-2217(94)00134-X

Gramani, M. C. N. (2012). Efficiency decomposition approach: A cross-country airline analysis. Expert Systems with Applications, 39(5), 5815-5819. https://doi.org/10.1016/j.eswa.2011.11.086

Hung, S. W., He, D. S., \& Lu, W. M. (2014). Evaluating the dynamic performances of business groups from the carry-over perspective: A case study of Taiwan' s semiconductor industry. Omega, 46, 1-10. https://doi.org/10.1016/j.omega.2014.01.003

Kottas, A. T., \& Madas, M. A. (2018). Comparative efficiency analysis of major international airlines using Data Envelopment Analysis: Exploring effects of alliance membership and other operational efficiency determinants. Journal of Air Transport Management, 70, 1-17. https://doi.org/10.1016/j.jairtraman.2018.04.014

Lampe, H. W., \& Hilgers, D. (2015). Trajectories of efficiency measurement: A bibliometric analysis of DEA and SFA. European Journal of Operational Research, 240(1), 1-21. https://doi.org/10.1016/j.ejor.2014.04.041

Liu, J., Zhu, J., \& Zhang, J. (2018). A DEA-based approach for competitive environment analysis in global operations strategies. International Journal of Production Economics, 203, 110-123. https://doi.org/10.1016/j.ijpe.2018.05.029

Lu, W. M., Wang, W. K., \& Kweh, Q. L. (2014). Intellectual capital and performance in the Chinese life insurance industry. Omega, 42(1), 65-74. https://doi.org/10.1016/j.omega.2013.03.002

Merkert, R., \& Pearson, J. (2015). A non-parametric efficiency measure incorporating perceived airline service levels and profitability. Journal of Transport Economics and Policy (JTEP), 49(2), 261-275. https://www.jstor.org/stable/jtranseconpoli.49.2.0261

Merkert, R., \& Williams, G. (2013). Determinants of European PSO airline efficiency-Evidence from a semiparametric approach. Journal of Air Transport Management, 29, 11-16. https://doi.org/10.1016/j.jairtraman.2012.12.002 
Morrell, P. S., \& Taneja, N. K. (1979). Airline productivity redefined: an analysis of US and European carriers. Transportation, 8(1), 37-49. https://doi.org/10.1007/BF00149850

Omrani, H., \& Soltanzadeh, E. (2016). Dynamic DEA models with network structure: An application for Iranian airlines. Journal of Air Transport Management, 57, 52-61. https://doi.org/10.1016/j.jairtraman.2016.07.014

Saranga, H., \& Nagpal, R. (2016). Drivers of operational efficiency and its impact on market performance in the Indian Airline industry. Journal of Air Transport Management, 53, 165-176. https://doi.org/10.1016/j.jairtraman.2016.03.001

Tone, K. (2001). A slacks-based measure of efficiency in data envelopment analysis. European journal of operational research, 130(3), 498-509. https:/ / doi.org/10.1016/S0377-2217(99)00407-5

Tone, K., \& Tsutsui, M. (2010). Dynamic DEA: A slacks-based measure approach. Omega, 38(3-4), 145-156. https://doi.org/10.1016/j.omega.2009.07.003

Tsionas, M. G., Chen, Z., \& Wanke, P. (2017). A structural vector autoregressive model of technical efficiency and delays with an application to Chinese airlines. Transportation Research Part A: Policy and Practice, 101, 1-10. https://doi.org/10.1016/j.tra.2017.05.003

Yu, M. M., Chang, Y. C., \& Chen, L. H. (2016). Measurement of airlines' capacity utilization and cost gap: Evidence from low-cost carriers. Journal of Air Transport Management, 53, 186-198. https://doi.org/10.1016/j.jairtraman.2016.03.005

Yu, M. M., Chen, L. H., \& Chiang, H. (2017). The effects of alliances and size on airlines' dynamic operational performance. Transportation Research Part A: Policy and Practice, 106, 197-214. https://doi.org/10.1016/j.tra.2017.09.015 